\title{
Ventilation Effects on Compartment Fire Characterization
}

\author{
MICHELLE J. PEATROSS and CRAIG L. BEYLER \\ Hughes Associates, Inc. \\ 3610 Commerce Dr., Suite 817 \\ Baltimore, MD 21227 USA
}

\begin{abstract}
Compartment fire experiments were performed using either natural or overhead forced ventilation to assess the effect of ventilation on the compartment fire environment. The ventilation rate was varied by changing the vent size in natural ventilation tests and mechanically in forced ventilation tests. Three fuels were used: diesel fuel, wood cribs, and polyurethane slabs. For naturally ventilated fires, it was noted that the vent size and geometry had a significant impact on the vertical temperature and oxygen concentration profiles. Both the temperature and oxygen concentration measurements were representative of two-layer environments. However, in terms of oxygen concentration, forced ventilation fires resulted in a well-mixed compartment regardless of the ventilation rate. In contrast, temperature measurements showed either a two-layer or linear variation with respect to compartment height, depending on the scenario. These results defy the conventional assumption that compartment temperatures and gas concentrations have the same vertical distribution. Furthermore, these results identify the need to go beyond the classic twolayer paradigm. In addition, reduced oxygen concentrations at the flame base resulted in reduced mass loss rates. The relationship between these burning rates and the oxygen concentration at the flame base was examined, and a correlation was developed. The results show that temperature and flashover potential assessments based on furniture calorimeter data may be significantly overestimated.
\end{abstract}

KEY WORDS: Zone model, burn rate, forced ventilation, natural ventilation, compartment fire

\section{INTRODUCTION}

Traditionally, it has been assumed that both naturally ventilated fires and forced ventilation fires result in two-layer environments. As a result, these fires are generally characterized using the classic two-zone fire model [1]. However, it is unclear whether this assumption is accurate for forced ventilation fires. 
Beyler performed a unique analysis for fires with overhead forced ventilation that assumed the fire compartment was well-mixed. Using this assumption, compartment temperatures resulting from fires with overhead forced ventilation were successfully predicted [2]. Beyler's assumption of well-mixed conditions was based on thermal profile data. For naturally ventilated fires, temperature profiles usually show a distinct upper and lower layer where the lower layer consists of "fresh" air and the upper layer consists of fire exhaust gases. Forced ventilation fires have shown different thermal characteristics depending on where the air is introduced and how well the fire is ventilated. Alvares et al. conducted experiments in which the forced ventilation was provided low in the compartment [3]. Temperature profiles were indicative of a two-layer environment although the interface location was not clear. Backovsky et al. performed similar experiments for fires with ventilation introduced both low and high in the enclosure [4]. The results from tests with both air-inlet locations indicate that the thermal profile characteristics are dependent on the ventilation rate. In the case of the low air-inlet configuration, higher ventilation rates were indicative of two-layer environments while lower ventilation rates were indicative of one-layer environments. The opposite effect was noted for the high air-inlet configuration. Since the relationship between thermal characteristics and gas species is not known, vertical oxygen concentration measurements are needed to identify what assumptions are truly valid. It is important to understand these characteristics so that forced ventilation fires can be modeled more effectively.

In order to characterize fires in an enclosure with different ventilation configurations more accurately, a series of experiments was conducted on the United States Coast Guard Test Vessel MAYO LYKES. The development of thermal and gas species profiles in different fire scenarios was examined. Both natural and forced ventilation experiments were conducted with different ventilation rates. Natural ventilation rates were changed by varying the vent size and geometry, and forced ventilation rates were changed mechanically. In addition, three fuel types were investigated to determine the effect of fire growth rate on the compartment characteristics. These experiments are unique in that both vertical oxygen concentration and temperature profiles were measured.

\section{EXPERIMENTAL SETUP}

The test compartment was approximately $3.4 \mathrm{~m}$ wide by $3.3 \mathrm{~m}$ deep by $3.05 \mathrm{~m}$ high (Figure 1 ) and was bounded by steel. All bulkheads were $12.7 \mathrm{~mm}$ thick with the exception of the port bulkhead which was $15.9 \mathrm{~mm}$ thick. A fuel cradle, $2 \mathrm{~m}$ by $2 \mathrm{~m}$, was suspended in the center of the compartment by a cable extending through the upper deck. A load cell was attached to the cable so the mass loss could be monitored.

The three vent configurations used in the natural ventilation test series represented an open door, a quarter door, and an open window. In order to simulate the quarter door and window vents, steel plates were placed over the appropriate portion of the doorway. The door vent was $0.9 \mathrm{~m}$ wide by $2 \mathrm{~m}$ high, the quarter door vent was $0.225 \mathrm{~m}$ wide by $2 \mathrm{~m}$ high and the window vent was $0.9 \mathrm{~m}$ wide by $0.8 \mathrm{~m}$ high. Both the door vent and quarter door vent were flush with the floor while the window vent had a sill of $1.2 \mathrm{~m}$. 


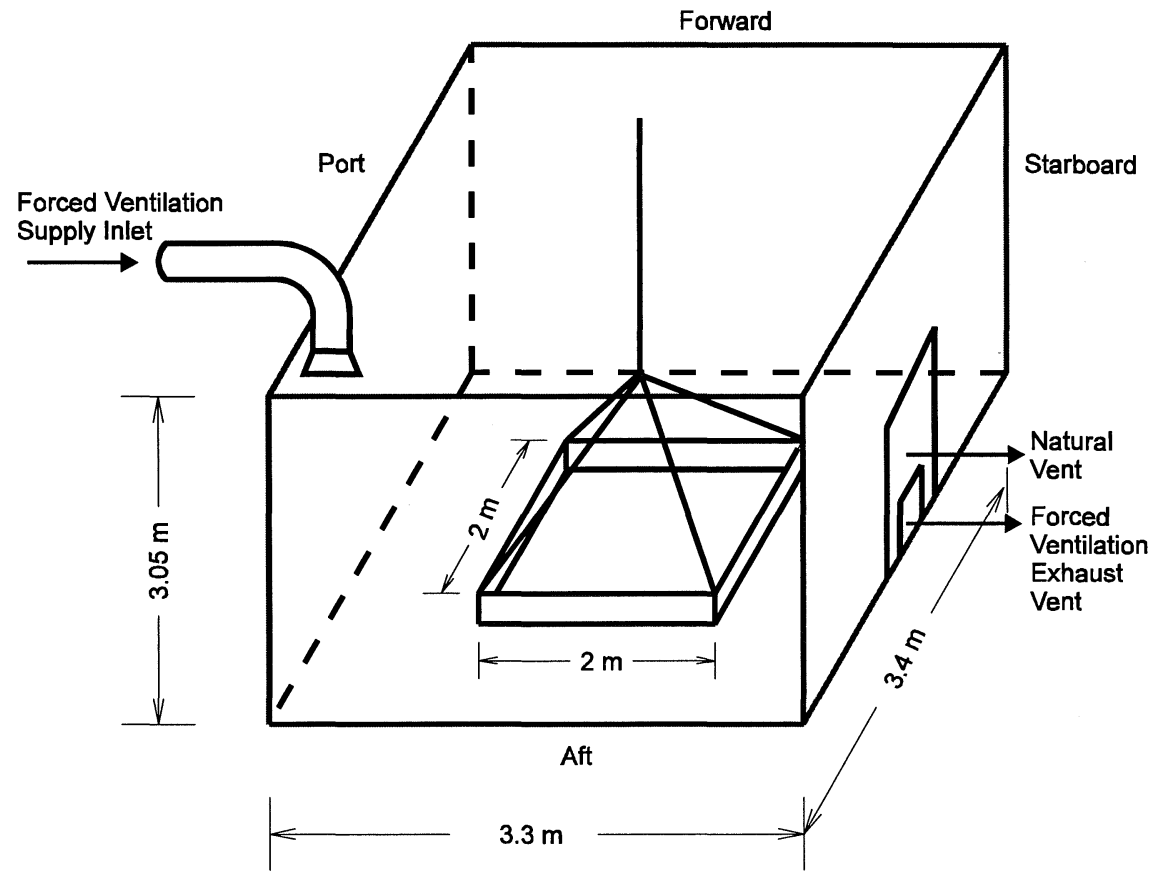

FIGURE 1. Isometric of test compartment

Ventilation was supplied to the room in forced ventilation tests via $30 \mathrm{~cm}$ diameter ductwork which extended from a supply fan. The supply duct discharged through the ceiling of the test room and a $42 \mathrm{~cm}$ by $42 \mathrm{~cm}$ diffuser was attached to the discharge hole to help disperse the air. Three ventilation rates were used: $0.29,0.45$ and $0.74 \mathrm{~kg} / \mathrm{sec}$. Exhaust products exited the compartment through a $28 \mathrm{~cm}$ by $28 \mathrm{~cm}$ vent which was flush with the deck (i.e., no sill).

Bi-directional probes and thermocouples were used to measure the vent flow rates in the natural ventilation tests. In the forced ventilation tests, the ventilation rate was measured using a bidirectional probe and thermocouple located in the supply duct. There were two thermocouple trees used to measure gas temperatures. Both trees were located in corners of the compartment and consisted of 10 branches spaced $30 \mathrm{~cm}$ apart. The first tree was located $0.35 \mathrm{~m}$ from the forward bulkhead and $0.6 \mathrm{~m}$ from the port bulkhead. The second tree was located $0.35 \mathrm{~m}$ from the aft bulkhead and $0.8 \mathrm{~m}$ from the starboard bulkhead. At this same location, a tree consisting of 7 branches was used for gas analysis. These branches were spaced $41 \mathrm{~cm}$ apart beginning 31 $\mathrm{cm}$ from the ceiling. Oxygen concentrations were measured at each location. A more detailed description of the test setup may be found in References 5 and 6 .

Tests were divided into two series. There were 12 tests which used natural ventilation and 12 tests which used forced ventilation. Within each series, three different vent sizes or ventilation rates were examined in conjunction with four fuel configurations. Fuel types included diesel pans, 
wood cribs, and polyurethane slabs. Two pan diameters, $84 \mathrm{~cm}$ and $62 \mathrm{~cm}$, were used for the diesel pan fires. The wood cribs were 1.9 by $1.9 \mathrm{~m}$ and consisted of six layers of 28 members ( $3.8 \mathrm{~cm}$ thick) spaced $3.1 \mathrm{~cm}$ apart. Polyurethane slabs measured $2 \mathrm{~m}$ by $2 \mathrm{~m}$ by $0.15 \mathrm{~m}$.

\section{RESULTS}

Table 1 shows burning rate results from both natural and forced ventilation tests. For natural ventilation tests, the vent configuration is included in addition to the ventilation rate. These ventilation rates were calculated using bi-directional probe data. For a given vent configuration, the ventilation rate was relatively constant between tests with different fuels. As would be expected, these rates are less than the values calculated using $A \sqrt{ } \mathrm{h}$, which assumes that the flow

TABLE 1. Fuel burning rate results for natural and forced ventilation tests

\begin{tabular}{||c|c|c|c|c||}
\hline Fuel Type & $\begin{array}{c}\text { Ventilation } \\
\text { Configuration }\end{array}$ & $\begin{array}{c}\text { Ventilation Rate } \\
(\mathrm{kg} / \mathrm{sec})\end{array}$ & $\begin{array}{c}\text { Burn Rate } \\
(\mathrm{g} / \mathrm{sec})\end{array}$ & $\begin{array}{c}\text { Upper Layer } \\
\text { Temperature (C)* }\end{array}$ \\
\hline \hline \multirow{3}{*}{$62 \mathrm{~cm}$ diameter pan } & door & 0.9 & 7 & 165 \\
& window & 0.28 & 8 & 195 \\
& $1 / 4$ door & 0.28 & 5 & 190 \\
\hline \multirow{3}{*}{$84 \mathrm{~cm}$ diameter pan } & door & 0.9 & 18 & 260 \\
& window & 0.28 & 9 & 230 \\
& 1/4 door & 0.28 & 11 & 260 \\
\hline \multirow{3}{*}{ Polyurethane slab } & door & 0.9 & 40 & 380 \\
& window & 0.28 & 20 & 360 \\
& 1/4 door & 0.28 & 25 & 340 \\
\hline \multirow{3}{*}{62 cm diameter pan } & door & 0.9 & 100 & 520 \\
& window & 0.28 & 30 & 380 \\
& forced & 0.28 & 40 & 400 \\
\hline \multirow{3}{*}{84 cm diamer } & 0.29 & 4 & 155 \\
& & 0.45 & 5 & 160 \\
& & 0.74 & 6 & 160 \\
\hline \multirow{3}{*}{ Polyurethane slab } & forced & 0.29 & 6 & 220 \\
& & 0.45 & 8 & 215 \\
& & 0.74 & 10 & 225 \\
\hline \multirow{3}{*}{ Wood crib } & forced & 0.29 & 10 & 260 \\
& & 0.74 & 14 & 250 \\
& & 0.45 & 20 & 260 \\
\hline \hline
\end{tabular}

* For forced ventilation tests, this quantity represents the compartment temperature (i.e., averaged over the entire compartment height). 
is choked [7]. The ventilation rate, measured in the supply duct, has been included for those tests with mechanical ventilation. Average upper layer temperatures are listed to add insight to the radiative heat feedback contribution to the burn rate. These values were obtained by averaging the steady-state temperature measurements that were located above the layer interface in the naturally ventilated tests. In contrast, the layer interface was not definable in the forced ventilation tests; consequently, temperatures were averaged over the height of the compartment.

In all natural ventilation tests, with the exception of the $62 \mathrm{~cm}$ diameter pan test with the window vent, the burn rate was lower for window and quarter door vent tests than those with the door vent. This is logical since the vent area was smaller and there was a 66 percent reduction in the ventilation rate. However, even though the window and quarter door vent tests had the same measured ventilation rate, the burning rates were generally lower for the window vent tests.

The forced ventilation test results show that the burn rate increases with increasing ventilation rate. The reduction in burn rate observed with lower ventilation rates may be falsely attributed to a reduction in the radiation feedback from the upper layer. However, the upper layer temperatures show that this is not the case for the pan and polyurethane fires. The upper layer temperatures measured at each ventilation rate are nearly identical for a given fuel. Wood crib fire tests were the only tests which indicated that the burning rate was affected by the radiation feedback from the upper layer. Due to the geometry of wood cribs and their reliance on internal radiation, wood crib burning rates are known to be unaffected by external radiation. Based on all of the results, it can be seen that the burning rates are determined by the fuel type and the ventilation rate, and not by the external radiation from the compartment.

\section{Natural Ventilation Test Profiles}

Vertical oxygen and temperature profiles were determined based on steady-state values for the pan and wood crib fires. Due to the nature of the polyurethane fires, the heat release rate peak was too short to represent steady-state conditions. As a result, the oxygen and temperature measurements, used to generate the profiles, correspond to this peak.

Figure 2 shows the oxygen concentration and temperature profile data for the natural ventilation tests. These data indicate that two-layer compartment characteristics existed in all tests, both thermally and chemically. For a given test, the shape of the oxygen concentration and the temperature profiles is the same. It is interesting to note that in all but two tests, the oxygen concentration at the flame base was less than 21 percent by volume. The two tests in which the entrained concentration was 21 percent by volume were the two diesel pan fire tests with a full door vent corresponding to the two smallest fuel loads and the highest ventilation rate. This observation indicates that compartment mixing was sufficient to reduce the oxygen concentration at the flame base below 21 percent.

In some cases, it is evident that the two-layer thermal characteristics are less defined for fires with window vents and quarter door vents. This trend is particularly clear in the $62 \mathrm{~cm}$ diameter pan tests. The change in slope, which is indicative of the layer interface, is not as prominent for the window and quarter door vent tests as it is for the door vent test. This same trend is observed in the oxygen concentration profiles. In addition to losing some of the two-layer traits, the oxygen concentrations at the flame base are lower for the tests with window and quarter door 

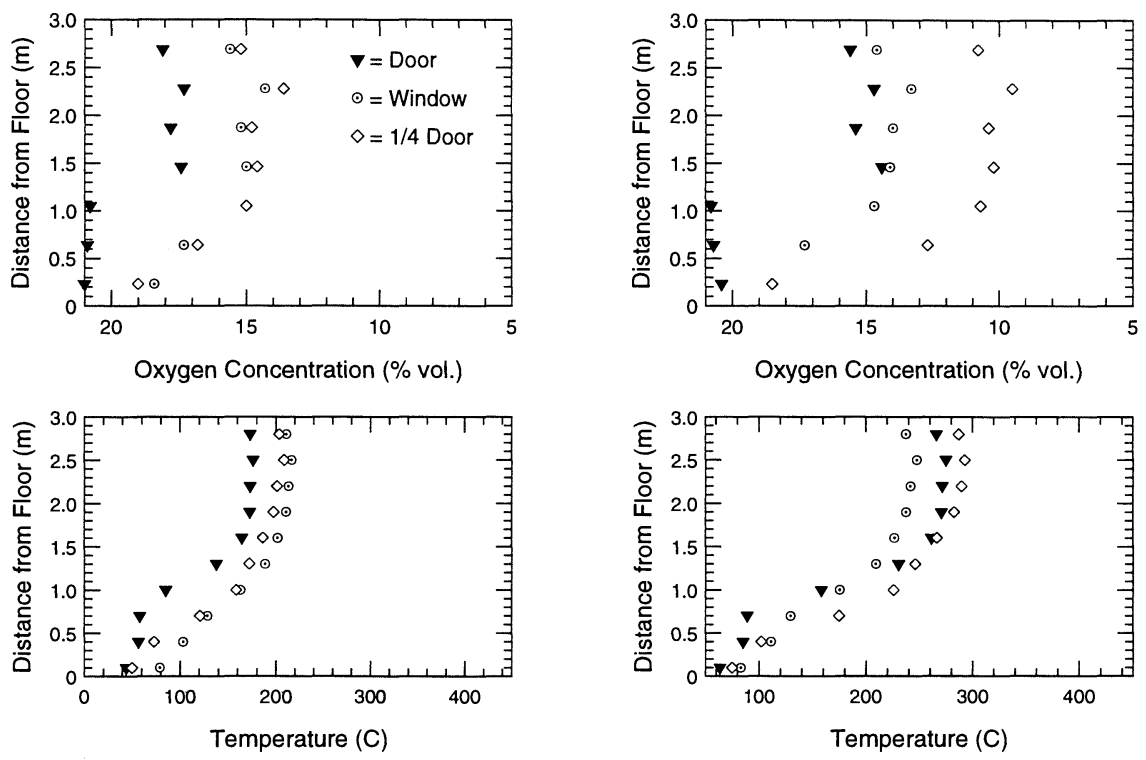

$62 \mathrm{~cm}$ diameter pan
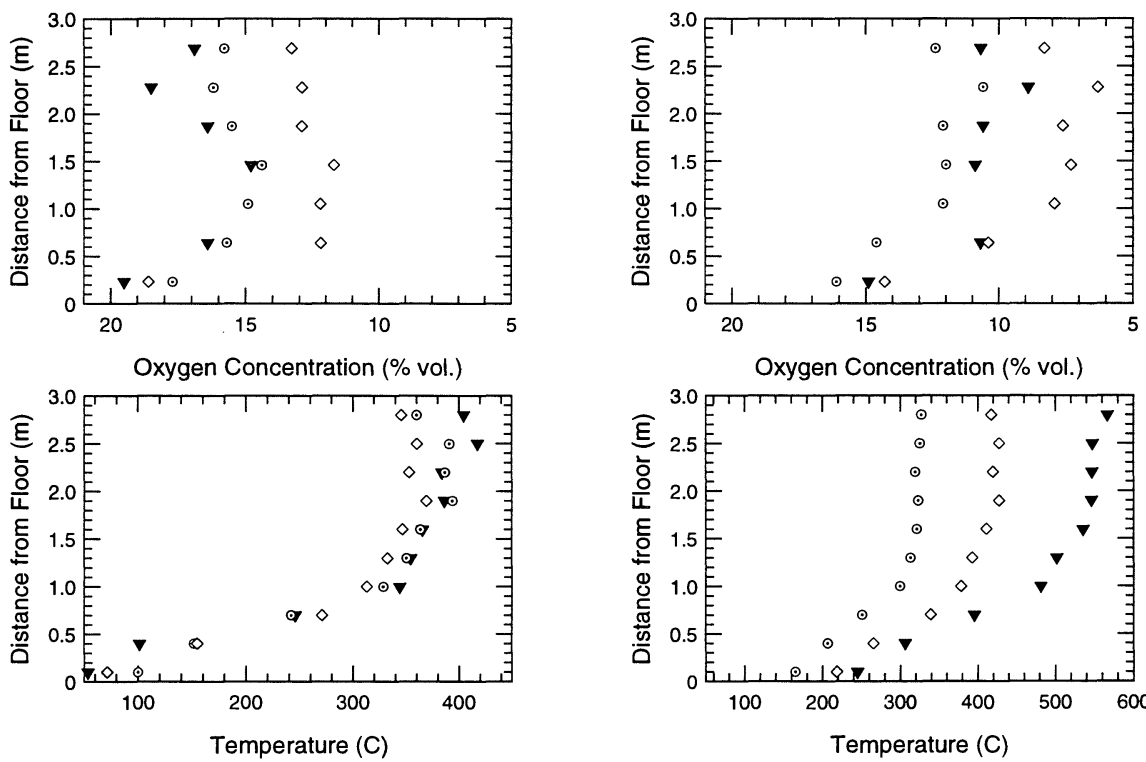

Polyurethane slab

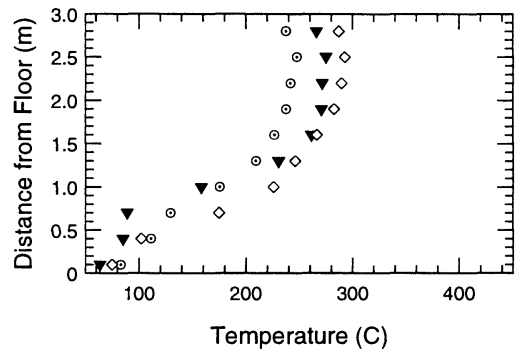

$84 \mathrm{~cm}$ diameter pan

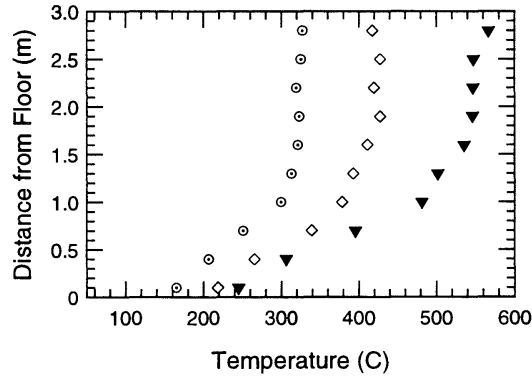

Wood crib

FIGURE 2. Oxygen concentration and temperature profiles for tests with natural ventilation 
vents. This result emphasizes that more mixing took place in these configurations versus the full door vent configuration.

In general, natural ventilation test results show that the size and geometry of the vent in a fire compartment will not only reduce the quantity of air available for combustion, but can also increase the amount of mixing which takes place before the air is entrained. This is a significant result because the reduced oxygen concentrations at the flame base can dramatically reduce the burning rate [8-10].

\section{Forced Ventilation Test Profiles}

Figure 3 includes the temperature and oxygen concentration profiles for the forced ventilation tests. It is evident from these graphs that there were no forced ventilation tests in which the oxygen concentrations at the flame base were at ambient levels (i.e., 21\%). The oxygen concentration profiles are nearly constant in all tests, indicating well-mixed environments. In some tests, such as the $84 \mathrm{~cm}$ diameter pan tests, the oxygen concentration may vary by as much as 2 percent by volume at different locations. For practical purposes, this variation is not considered to be significant. The overall trend was that the oxygen concentration increased as the ventilation rate increased.

Temperature profiles were generally indicative of two-layer environments. In the $62 \mathrm{~cm}$ diameter pan fires, the profiles were nearly linear and could be considered well-mixed, where well-mixed implies that there is no layer interface. Other fires, particularly the polyurethane and wood crib fires, showed thermal behavior which was between a clean two-layer and well-mixed system. For modeling purposes, this type of profile would typically be labeled as two-layer. These profiles were remarkably similar to those measured in the natural ventilation tests, yet the oxygen concentration profiles are dramatically different for the two configurations. In natural ventilation tests, the oxygen concentrations showed a definite stratification whereas, in forced ventilation tests, no stratification is apparent. It is also interesting to note that the thermal conditions are independent of the ventilation rate for all fuels except the wood cribs. This effect is noted at all heights in the compartment as demonstrated by the temperature profiles which nearly collapse together for a particular fuel.

These temperature profiles are similar to those observed by Backovsky in experiments where the air-inlet was high [4]. As previously discussed, linear profiles were observed for over-ventilated fires while two-layer profiles were observed for under-ventilated fires. Based on the results of the present work, it would be expected that gas species were well-mixed in Backovsky's tests regardless of the temperature profiles. These results are not expected to generalize to other forced ventilation scenarios where the ventilation is not provided high in the compartment. By introducing the air through the ceiling, it must mix with the exhaust gases prior to fire entrainment. 

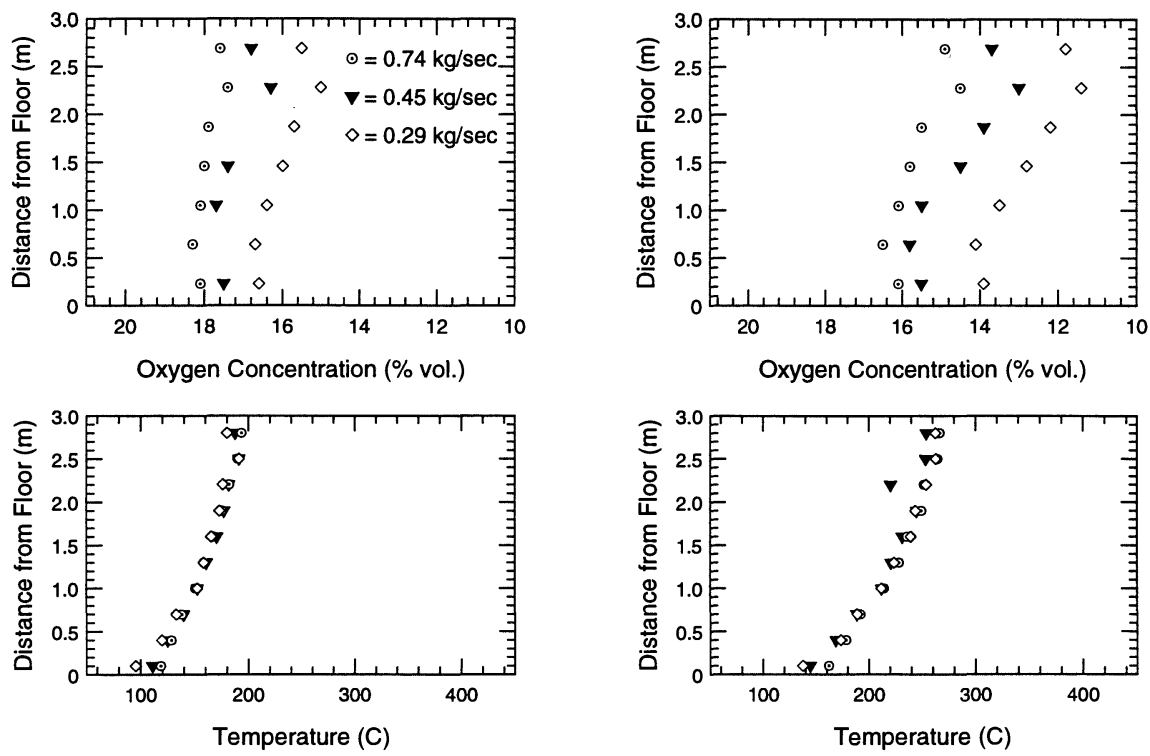

$62 \mathrm{~cm}$ diameter pan

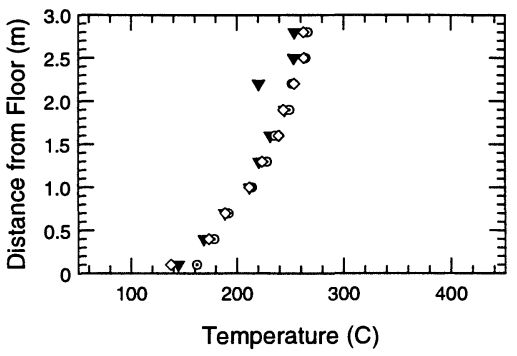

$84 \mathrm{~cm}$ diameter pan
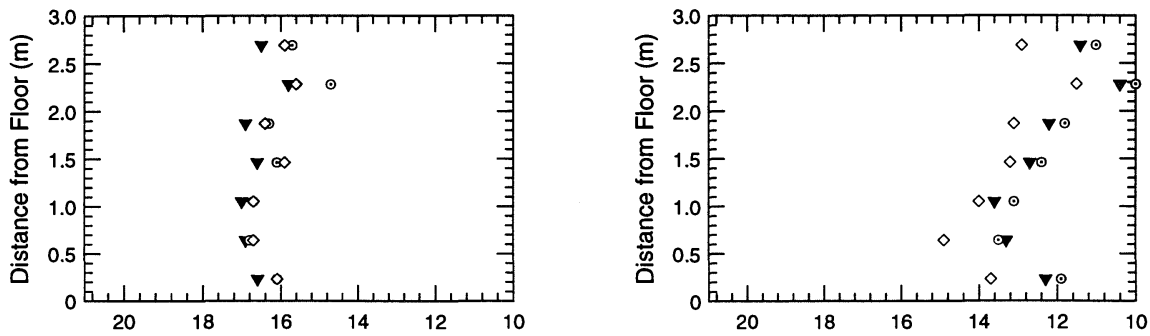

Oxygen Concentration (\% vol.)

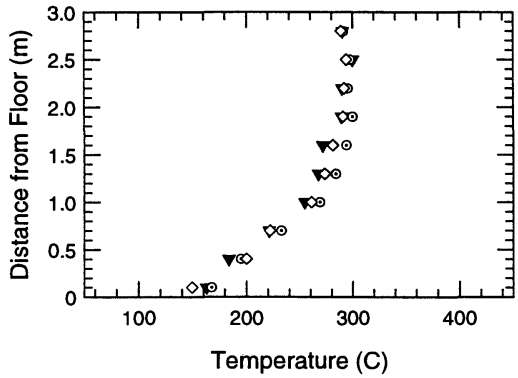

Polyurethane slab

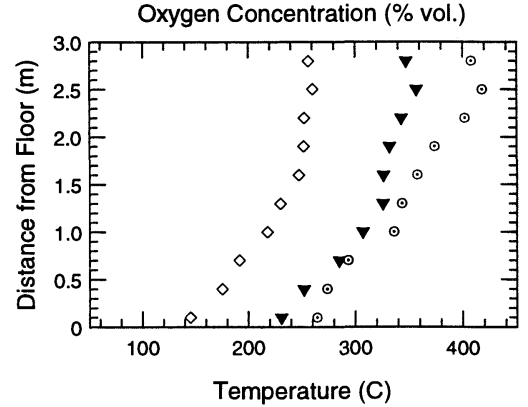

Wood crib

FIGURE 3. Oxygen concentration and temperature profiles for tests with forced ventilation 
As stated above, the compartment temperatures were independent of the ventilation rate with the exception of the wood crib fires. In order to understand this, a simple energy balance may be examined:

$$
\Delta T=\frac{\dot{Q}}{\dot{m}_{e x} c_{p}+h_{k} A_{t}}
$$

where the temperature rise in the compartment $(\mathrm{K})$ is expressed as a function of the heat release rate $(\dot{Q}$ in $\mathrm{W})$, compartment exhaust rate $\left(\dot{\mathrm{m}}_{\mathrm{ex}}\right.$ in $\left.\mathrm{m}^{3} / \mathrm{sec}\right)$, heat capacity of the exhaust gases $\left(\mathrm{c}_{\mathrm{p}}\right.$ in $\mathrm{J} / \mathrm{kgK})$, overall heat transfer coefficient $\left(\mathrm{h}_{\mathrm{k}}\right.$ in $\left.\mathrm{W} / \mathrm{m}^{2} \mathrm{~K}\right)$, and the surface area of the compartment boundaries $\left(\mathrm{A}_{\mathrm{t}}\right.$ in $\left.\mathrm{m}^{2}\right)$. The only parameters in this equation which change considerably between ventilation rates are the burn rate (or the heat release rate) and the compartment exhaust rate. In order for the temperature change to remain constant for each configuration, these values would have to change at a rate such that their effects cancel out each other. It seems coincidental that these two parameters change at these rates and that temperature profiles will truly be independent of the ventilation rate. Certainly, there are not enough results to be conclusive.

\section{Effect of Oxygen Concentration on Burning Rates}

Several studies have been published in which the effect of the ambient oxygen concentration on the flame properties was examined [8-10]. Tewarson et al. performed small-scale experiments that examined the effect of oxygen concentration on various fuel parameters (i.e., mass loss rate, combustion efficiency, gas species yields, and convective and radiative fractions of heat of complete combustion) in pool fires [8]. Several fuels were used including PMMA and heptane. Many of these tests were conducted with oxygen enriched environments; however, there are data which were recorded for reduced oxygen environments. These experimental data show that as the oxygen concentration was reduced, the burn rate was reduced. Santo and Tamanini conducted experiments similar to those of Tewarson using PMMA as the fuel [9]. The relationship between oxygen concentration and burning rate was consistent with that observed by Tewarson.

Since the mass loss rate per unit area, $\dot{\mathrm{m}}^{\prime \prime}$, may vary significantly for different fuels, a more general approach may be used by normalizing these values. For a given fuel and fuel size, this can be done by normalizing with the mass loss rate per unit area that results from burning in normal oxygen concentrations, $\dot{\mathrm{m}}_{21}{ }^{\prime \prime}$ (i.e., $21 \%$ ). This may help account for some of the variation in fuel properties. Figure 4 shows the relationship between these normalized burning rates per unit area as a function of the oxygen concentration at the flame base. Included are data from the pan fire experiments with forced ventilation as well as small-scale data published by Tewarson [8] and by Santo [9]. The data agree well, and a linear correlation was developed:

$$
\frac{\dot{m}^{\prime \prime}}{\dot{m}_{21}^{\prime \prime}}=0.1 O_{2}[\%]-1.1
$$




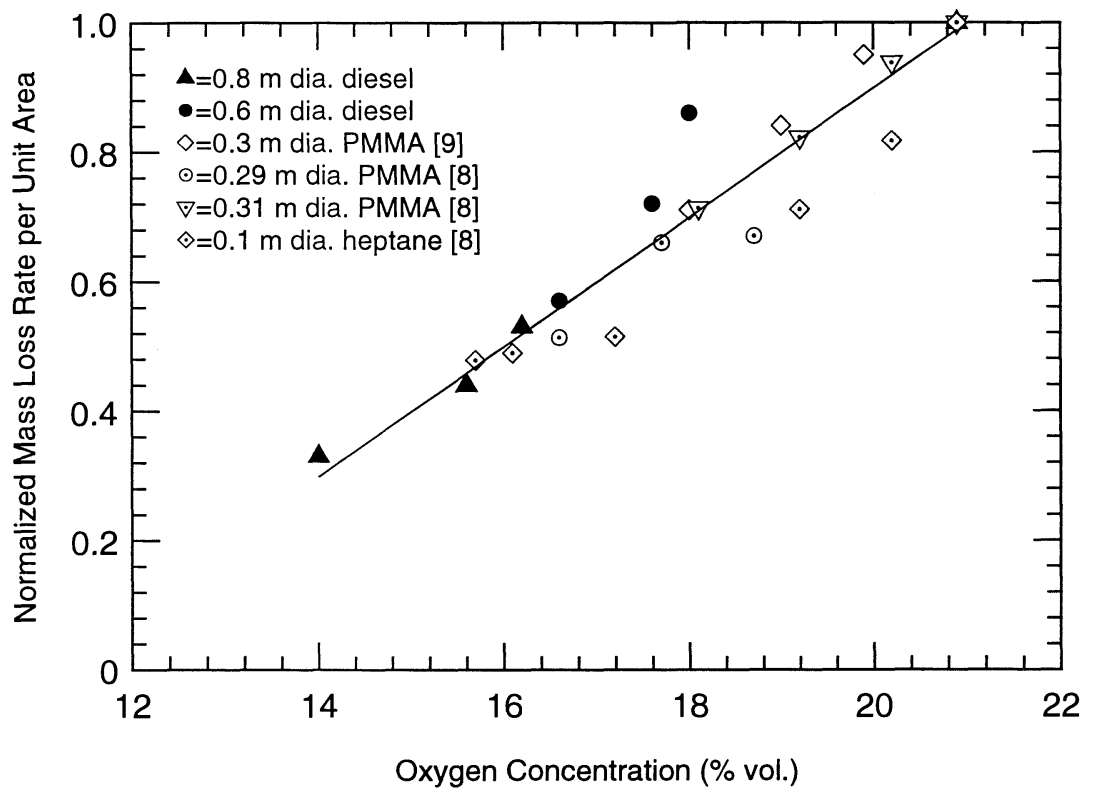

FIGURE 4. Effect of oxygen concentration on normalized mass loss rate per unit area

The reduced oxygen concentrations at the flame base in these tests resulted in burning rates as little as one-third of the nominal burning rate in air. Therefore, the practice of using furniture calorimeter data as input to fire models without consideration of oxygen concentrations at the flame base is questionable. In many cases, it will seriously overestimate compartment temperatures and flashover potential.

\section{CONCLUSIONS}

These results show unexpected temperature and oxygen concentration distributions for compartment fires. While typical two-layer oxygen concentration and temperature profiles were measured in naturally ventilated fire tests, profiles measured in forced ventilation tests were not as predictable. Oxygen concentration profiles indicated one-layer environments in all tests while temperature profiles suggested either one or two-layer environments, depending on the scenario. This observation shows that a fire compartment cannot be reliably characterized based on thermal data. These results suggest that the classical two-layer paradigm should be expanded. 
In addition, reduced oxygen concentrations were measured at the flame base in most tests. This phenomenon was observed even in fires which resulted in well-defined two-layer environments, both chemically and thermally. For naturally ventilated fires, oxygen concentrations were lower for quarter door and window vent tests, indicating that more compartment mixing took place than in full door vent tests. These compartment mixing effects result in reduced oxygen concentrations at the base of the fire, and this in turn results in reduced burning rates. A strong correlation between the entrained oxygen concentration and the normalized mass loss rate per unit area was observed. This correlation may be used to make less conservative predictions of fire behavior instead of the current practice of using furniture calorimeter data for the heat release rate.

\section{ACKNOWLEDGMENTS}

The authors wish to thank the USCG Marine Fire and Safety Research Division in Groton, CT for their support on this project. Also, they would like to express their appreciation to the Fire and Safety Test Detachment personnel in Mobile, AL for their dedication and cooperation.

\section{REFERENCES}

1. Quintiere, J.Q., "Fundamentals of Enclosure Fire 'Zone' Models," Journal of Fire Protection Engineering, 2 (2), 1990, pp. 33-48.

2. Beyler, C.L., "Analysis of Compartment Fires with Overhead Forced Ventilation," Proceedings of the Third International Symposium on Fire Safety Science, 1992, pp. 291300.

3. Alvares, N., Foote, K., and Pagni, P., "Forced Ventilated Enclosure Fires," Combustion Science and Technology, Vol. 39, 1984, pp. 55-81.

4. Backovsky, J., Foote, K., and Alvares, N., "Temperature Profiles in Forced-Ventilation Enclosure Fires," Proceedings of the Second International Symposium on Fire Safety Science, 1988, pp. 315-324.

5. Peatross, M.J., Beyler, C.L., and Back, G.G., "Validation of Full Room Involvement Time Correlation Applicable to Steel," United States Coast Guard Report No. CG-D-16-94, November 1993.

6. Peatross, M.J., and Beyler, C.L., "Thermal Environment Prediction in Steel-Bounded Preflashover Compartment Fires," Proceedings of the Fourth International Symposium on Fire Safety Science, 1994, pp. 205-216.

7. Drysdale, D., An Introduction to Fire Dynamics, John Wiley and Sons, New York, 1985.

8. Tewarson, A., Lee, J.L., and Pion, R.F., "The Influence of Oxygen Concentration on Fuel Parameters for Fire Modeling," Eighteenth International Symposium on Combustion, The Combustion Institute, 1981, pp. 563-570. 
9. Santo, G., and Tamanini, F., "Influence of Oxygen Depletion on the Radiative Properties of PMMA Flames," Eighteenth International Symposium on Combustion, The Combustion Institute, 1981, pp. 619-631.

10. Mulholland, G., Janssens, M., Yusa, S., Twilley, W., and Babrauskas, V., "The Effect of Oxygen Concentration on $\mathrm{CO}$ and Smoke Produced by Flames," Proceedings of the Third International Symposium on Fire Safety Science, 1991, pp. 585-594. 